\title{
Research on IT Service Management of Local Colleges Based on ITIL
}

\author{
Zhengang LI \\ Network center \\ Tianjin Institute of Urban Construction \\ Tianjin, China \\ lzhg@tjuci.edu.cn
}

\author{
Zhigang Zhang \\ Network center \\ Tianjin Institute of Urban Construction \\ Tianjin, China \\ zzg@tjuci.edu.cn
}

\begin{abstract}
At present, the key of IT work faces to convert construction to service, however, the local colleges have not established complete management in order to fit for these changes. This paper discusses on IT service management mechanism and implement scheme for local colleges after analyzed the problem of IT service management. The improvement method are proposed according to ITIL.
\end{abstract}

Keywords-IT Service Management; ITIL; Management Mechanism; Service Counter

\section{INTRODUCTION}

Informatization of universities have made remarkable achievement after long-term development, IT systems have turned into an important supporting platform for campus. With the rapid development of E-Campus, the network structure is increasingly complicated. Meanwhile, the scale of information system expands continuously and the number of users are increasing. The users raise more strict demands on the service quality of IT department. The results show that the 70 percent of lifecycle in IT project are operation and maintenance, therefore, the focus of IT department in colleges and universities are changing from construction to service gradually, so as to the quality of service for its users is more and more important[1]. IT management especially service management become more and more difficult, its level affects the effect of E-Campus system, especially in local college[2].

\section{INFLUENCE FACTORS OF IT SERVICE}

After investigate and survey in certain universities, the author finds that the influence factors of IT service management of local colleges mainly include such aspects:

\section{A. The rules and regulations are not strictly performed.}

The favorable network operation is ensured by a series of rules and regulations which make IT management methodically with high quality and network consistency and continuity. However, the different comprehension of IT service between users and engineers make the performance of rules and regulations difficultly.

\section{B. The ideas can't keep up with the development.}

As for IT engineers, the ratio of engineers to users is unreasonable in most colleges and universities, their service of operation and maintenance focuses on technical support and solution after the problem. The early warning and the consciousness of initiative service can not rapid carry out because of the passive onerous work. On the other hand, due to insufficiency of network knowledge, the IT work of campus users depend on IT department in significant measure, even if their work rarely relate to IT department. It means a serious accident involving serious consequences to IT department on account of the failure of crucial system in a short time, but the fact is not like this.

\section{Lack of scientific and effectiveness management in IT service.}

During the IT service operation, the problem that all engineers deal with immediately after receiving the failure reports can not be solve completely owing to lack of powerful coordination and management, whereas the repeated work occupied the 80 percent of their whole work, at the same time their IT service experience have not effective accumulation and development.

\section{The insufficient IT infrastructure management.}

Following the increment of scale and complexity, there are various hardware and software which operate integrated into network on end, in many ways, this is difficult for engineers who are required to go on maintaining the complex devices. From all above, the quality of IT service are affected with these factors.

\section{E. The insufficient IT service training.}

The engineer of IT department in local colleges are short of training in services, management, technic, especially in the quality and level of service.

\section{CONTENT OF IT SERVICE}

ITIL(Information Technology Infrastructure Library)has been successfully applied to IT service in many company. And it also has great progress in some leading universities, such as Sun Yat-sen University, Renmin University of China, etc. However, compared with the leading universities, IT service management in local colleges has a large gap in scale, investment, technique, users, requirement etc. So it still has a long way to go. On the other hand, IT service management in local colleges has its own characteristics, the content of IT service mainly include such aspects as follow :

This work was financially supported by the Tianjin Educational Science 12th Five-Year Planning Project (HEYP5012). 


\section{A. IT infrastructure service}

IT infrastructure service refers to IT infrastructure management, maintenance and the support of operations. Even though including Part-time staff or external personnel with different engineering level, the service team is still understaffing and inexperience, it is difficult to be satisfied with the requirement of their users.

\section{B. IT services in E-campus applications}

The E-campus platform is composed of a series of applications of teaching, research, personnel, recruiting and financial. Due to the system programing by different development platform, it is difficult to manage the heterogeneous information resources.

\section{The services management in Security}

The existing risks and X-scan can be solved by a reasonable cost according to the policy, strategy and method. IT infrastructure also can be protected by preventing unauthorized visits.

\section{Network access services}

As the main of the network along with the informationization construction has been established, the new requirements need to coordination and implementation with the some new network access and temporary access.

\section{E. Other integrated management services}

Associated with the IT-related integrated service management.

\section{IT SERVICE MANAGEMENT MECHANISM}

Currently, IT service management system in local colleges is not perfect, many colleges and universities have not established effective mechanism for information construction and management[3]. In contrast, the universities and colleges in the United States have better IT management mechanism than us[4]. Only a few leading Universities in our country have established CIO system, Combined with the characters of local colleges[5], we suggest our IT service management mechanism as figure1.

\section{A. Leadership mechanism}

1) Organization: Establishment of IT management leading organization, and its member is composed of the critical leaders of departments, such as personnel, finance, teaching, research, student management department. The organization is an university-level institution and is in the charge of president.

2) Responsibility: After accumulation of IT service management experience, the leading organization will make the policy of IT service management. The responsibility include: determining the campus IT management strategies, task and development direction, determining IT management budget and resource allocation, arranging, coordinating, ensuring the smooth implementation in accordance with strategies planning, consideration of IT management program.

\section{B. Review mechanism}

1) Organization: Establishment of IT management experts Committee, which is composed of internal and external professors and engineers who are IT specialists or management experts. The committee is an independence agency, which is under the IT management leading organization.

2) Responsibility: The committee is mainly responsible for campus IT management planning, program evaluation, and assessment of the efficiency and quality of IT services.

\section{Management mechanism}

1) Organization: Establishment of IT management center , which is leaded by IT management leading organization , is responsible for daily IT management. The department is made of management and technical personnel.

2) Responsibility: The center is mainly responsible for IT management planning, program development, and IT management and coordination, and forecast events to avoid incidence.

\section{Implementation mechanism}

1) Organization: The Implementation departments of IT management which consist of IT management center and related business departments cooperate with each other based on a series of rules and IT management leading organization.

2) Responsibility: IT management center is mainly responsible for technical support, including operational management and services. Operational management refer to network management, application system management, security management, configuration change management,computer room management, internal training management. Services refer to engineers on duty, on-site services, self-service, feedback tracking, computer room management, service training. Related business departments are responsible for the research, design, target assessment cooperated with IT management center[6].

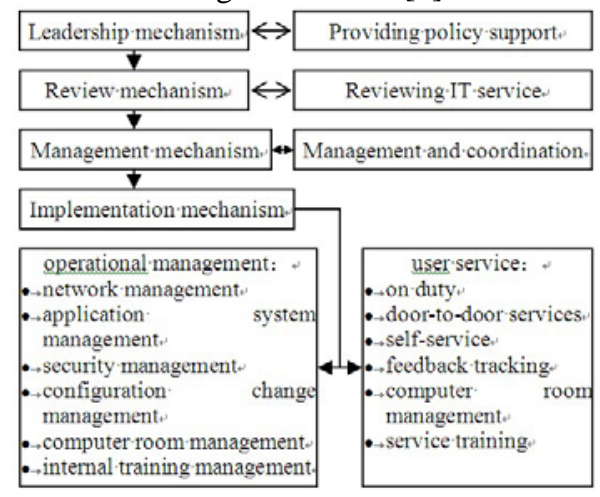

Figure1. IT service management mechanism

\section{IMPLEMENTATION SCHEME OF IT SERVICE MANAGEMENT}

We established counter service, which ensured the channel of service requests are unblocked and handled immediately 
with the role of the management mechanism. The engineers can pre-judge and treat the faults in order to " 5 minutes earlier" to find faults and improve the response speed by developed an IT Operations and Maintenance System. The IT services response rapidly and effectively by established a classification mechanism, event library, effective processes. The implementation process of IT services as shown in Figure 2.

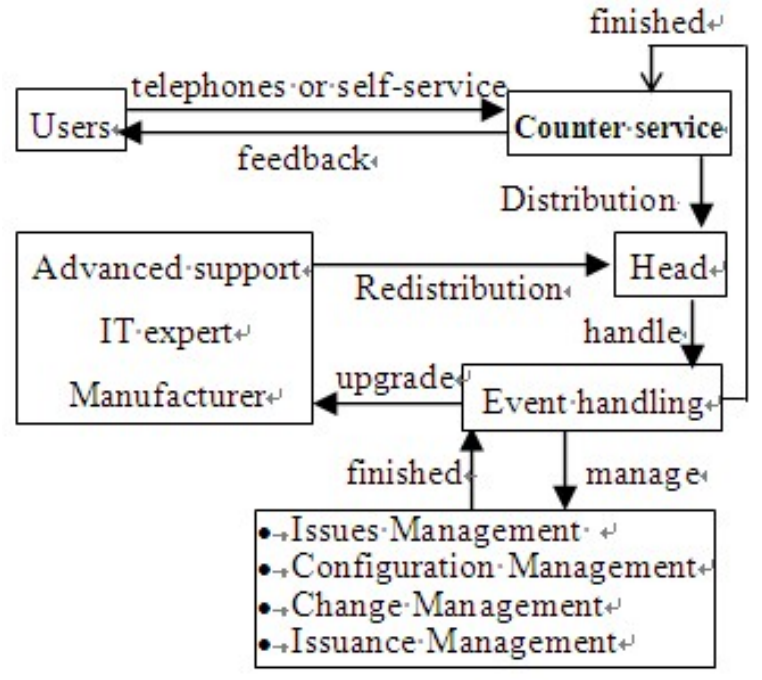

Figure 2. IT services implementation process

Users can submit questions to counter service by visiting, telephones or self-service platform. The operator do a preliminary judgment on the issues, if he can immediate solve the problems, he will give feedback to the user, or, he will register and assign the problem to the engineer. The engineers make relevant records and update the database of IT service after completed the task allocated by operator, the results can be feedback to the user by the counter service. If the problem is more complex, the engineers will fall back on the superior support, IT experts, manufacturers to obtain the proposed solution. Finally, the processing results are feedback to the user by counter service. The counter service is the only window of IT department. With this, users need not understand the process of internal IT department, The advice, questions and complaints are deal with the counter service in order to avoid the problems that users contact with engineer directly.

\section{THE PROBLEMS AND SOLUTION METHOD}

\section{A. Service dependency problem}

Due to the knowledge of IT in local collages at a low level, the comprehension of IT is not clear and definite, the things are required IT departments to do even if they had nothing relations with IT department, the service dependency appeared. After established management mechanism, the range of IT services have been clearly divided by official documents of IT management leading organization, the related departments perform their corresponding tasks according to the official documents. If any of IT services is unclear, the only explanation is official documents, The conflict of users and engineers are greatly relieved by the division between responsibilities and obligations.

\section{B. The stortage of IT serive managemnet funds}

In general, the trouble in local collages are shortage of IT service management funds. The financial Sources of informatization construction are mainly financial allocation and campus input, according to the policy requirements it can be used in construction, in fact, the budget did little for service management in local collages. The suggestion is network to support network, the money have been handed in campus finance, the funds are allocated to IT department as service management funds in a certain proportion based on official documents. IT departments re-use this part of the funds to improve the condition of network and quality of service, this way not only reduces the burden on the campus, but also make a virtuous cycle in IT service management.

\section{The shortage of IT engineer}

The shortage of IT engineer is common problem in most local colleges. For a long time, compared with professional teachers, IT engineers are faced a disadvantage condition in salary and position, at the same time IT work need the engineer with high level of technical ability, So it makes a strange situation: teachers with high IT technology reluctant to do these work. To this problem, the suggestion is external engineers introduction mechanism. The engineer with high IT technology are hired by IT department even if they had not have high education, their treatment rely on intermediary organs of talents, so as to improve the quality of IT service rapidly in local colleges.

\section{CONCLUSIONS}

As ITIL have Standardized methodologies and processes, it can effectively solve the problems in IT management. The management mechanism and implementation methods according to ITIL by its own characteristics will not only minimize the management and operating costs of IT facilities , but also maximize the effect of informationization in a limited investment situation for local colleges.

\section{REFERENCES}

[1] Jan van Bon.IT Service Management, an introduction based on ITIL[M], TsingHua University Press, Beijing, P.R.China, 2006:26.

[2] LIU Hai-feng, LIAN Yi-feng. Security service level management based on ITIL. Computer Engineering and Design, 2007,28(4):780-784,868.

[3] Yang Man-fu. On problems of IT governance in colleges and universities, Academic Forum, 2008,206(3):190-192.

[4] Sauve J., Moura A., Sampaio M.. An introductory overview and survey of business-driven IT management. Information Technology Management from a Business Perspective, 2006: 1-10.

[5] Zhang Cheng-hong, Information construction and management of universities, Tongji University Press, Shanghai, P.R.China,2006:9-14.

[6] Sun Qiang, Discussion on informatization construction mechanism of universities, China Education Info, 2010.01:10-12 